\section{Catastrophic spending on health care in Brazil: private health insurance does not seem to be the solution}

\author{
Gasto catastrófico com saúde no Brasil: planos \\ privados de saúde não parecem ser a solução
}

Aluísio J. D. Barros 1

João Luiz Bastos 2

Andréa H. Dâmaso 3

\section{Introduction}

The objective of this study was to estimate catastrophic healthcare expenditure in Brazil, using different definitions, and to identify vulnerability indicators. Data from the 2002-2003 Brazilian Household Budget Survey were used to derive total household consumption, health expenditure and household income. Socioeconomic position was defined by quintiles of the National Economic Indicator using reference cut-off points for the country. Analysis was restricted to urban households. Catastrophic health expenditure was defined as expenditure in excess of $10 \%$ and $20 \%$ of total household consumption, and in excess of $40 \%$ of household capacity to pay. Catastrophic health expenditure varied from $2 \%$ to $16 \%$, depending on the definition. For most definitions, it was highest among the poorer. The highest proportions of catastrophic health expenditure were found to be in the Central region of Brazil, while the South and the Southeast had the lowest. Presence of an elderly person, health insurance and socioeconomic position were associated with the outcome, and coverage by health insurance did not protect from catastrophic health expenditure.

Health Expenditures; Health Services; Prepaid Health Plans;
Catastrophic health expenditure is present when a "household must reduce its expenditures over a period of time to cope with health costs, although no consensus is available on the threshold proportion of household expenditure" 1 (p. 111). Regardless of the fact that excessive health expenditure and catastrophic health spending have been inconsistently defined and measured across a number of international studies, there is increasing evidence that both stand as factors that can negatively impact the achievement of health equity and may contribute to the impoverishment of population groups, especially those lower down the social scale 2,3,4,5,6.

Recent data from studies carried out in India 5, Georgia 4, China 2, the United States 6 and Turkey ${ }^{3}$ show that out-of-pocket health expenditure and catastrophic health spending may put individuals and families at financial risk. These studies demonstrate that major determinants of out-of-pocket expenditure and/or catastrophic health spending are hospitalization of a household member 4 , the presence of chronically ill ${ }^{4}$ or elderly ${ }^{6}$ members within the household, and the localization of the household in rural areas 5 , as compared to urban ones. Drugs or medicines account for $70 \%$ of total out-of-pocket expenditure in some cases 5 .

A multi-country analysis by Xu et al. 1 revealed that catastrophic health spending, for example, 
is also a matter of concern in South America, with Brazil as one of the countries showing the highest proportion of families experiencing catastrophic health expenditure worldwide. Additional evidence from Brazil 7, specifically from its southernmost region, indicated that about $16 \%$ of households from a low-income population in the city of Porto Alegre in Rio Grande do Sul State spent $20 \%$ or more of their incomes on health. In the context of primary care oriented health systems, such as the Brazilian Unified National Health System (SUS), excessive health expenditure may represent inefficient ways of financing health care, if not system failures in providing free, equitable and universal care to all citizens, and especially to the neediest.

The suggestion that Brazil has a high proportion (about 10\%) of families experiencing catastrophic health spending ${ }^{1}$ warrants further exploration of the topic in this country. There are no published studies investigating the magnitude of health spending according to household socioeconomic position, nor its major determinants from a country-wide perspective. Such analyses would enable comparisons among Brazilian regions, so as to provide a detailed picture of excessive health spending in Brazil. The 2002-2003 Brazilian Household Budget Survey (POF), a sophisticated and detailed survey, which sought to assess the expenses, budgets and savings of more than 40,000 Brazilian households, provides a unique opportunity for such an investigation.

The objective of the present study, therefore, was to assess excessive and catastrophic health spending, according to household socio-economic position and region of residence, as well as to assess their predictors in Brazil.

\section{Methods}

Data from the POF, carried out between July 2002 and June 2003, by the Brazilian Institute of Geography and Statistics (Instituto Brasileiro de Geografia e Estatística - IBGE) were used for this study. This survey was designed to cover the whole country, using a stratified two-stage sampling procedure. Census tracts defined for the 2000 Brazilian Demographic Census were used as primary sampling units, while households were the secondary ones. Selection of primary sampling units was done with probability proportional to size by systematic sampling, and households through simple random sampling. Selected primary sampling units were distributed along the 12-month data collection period, so that there was data collection in all strata during the whole period. Stratification was used to assure an even distribution of the sample across urban and rural areas. In each state there were three urban strata: capital city, metropolitan region (excluding the capital), and remaining urban areas. For rural areas, five strata were defined, one for each top-level geographic region (North, Northeast, Central, Southeast and South). Within each geographic stratum, economic stratification was based on schooling of the head of household. Sample size was defined relative to coefficients of variation of pre-specified variables and was set at 44,248 households. This number was increased by $30 \%$ to allow for selection of unoccupied or non-residential buildings and refusals. In the end, 60,911 households were selected and 48,470 were enrolled (loss of $20.4 \%$ ). In the present analysis, only urban households were studied, totaling 37,830 .

Standardized questionnaires were used to collect information on: (i) residents' characteristics (sex, age, self-reported color/race, schooling, height, weight); (ii) household characteristics (size, building materials, sanitation, ownership); (iii) self-assessed living conditions; (iv) household and personal expenditures (collected item by item); and (v) monetary and non-monetary income (collected for each resident). Different reference periods were used for each type of expense: 7, 30 and 90 days and 12 months prior to the date of interview. The reference period for expenses with medicines was 30 days and for health care was 90 days. Income was investigated for a full 12-month period. All monetary values were deflated for a reference date (15/Jan/2003) and annualized. A comprehensive account of the survey methods is presented elsewhere (IBGE. POF 20022003: Primeiros resultados. http://www.ibge. gov.br/home/estatistica/populacao/condicao devida/pof/2002/pof200220032aed.pdf, accessed on Dec/2010).

All expenses were first corrected for inflation and annualized in order to calculate the total expenditure by item. Data were collected by IBGE in groups and we added total household consumption for: food (excluding alcoholic drinks), health care, medicines, and all other expenditures. Total household consumption was estimated adding up all groups.

The economic classification was done using the National Economic Indicator (IEN in Portuguese), an asset index proposed by Barros \& Victora 8 that has reference distributions described for the whole country, and all Brazilian states and state capitals. The index was created through principal components analysis, using 13 asset indicators available in the 2000 Demographic Census. IEN was calculated for all households, which were then assigned to 
reference quintiles calculated for the whole country. The use of IEN quintiles for socio-economic position comparisons instead of using quintiles of household consumption is justified by the use of household consumption as the denominator of estimates for catastrophic expenditure. This would produce a correlation that would be, in part, just an artifact.

Situations of excessive health expenditure were identified using three criteria: total household health expenditure (including health care and medicines) in excess of $10 \%$ and of $20 \%$ of household consumption, and in excess of $40 \%$ of household capacity to pay (calculated in relation to consumption and to income), an approach similar to that by Wagstaff \& van Doorslaer study 9 . Household income was estimated by adding the reported monetary inputs by all residents. Household capacity to pay was estimated as household consumption (or income) less its subsistence expenditure. In cases in which this calculation led to a negative value, household consumption was estimated as household consumption (or income) less food consumption.

Per capita subsistence expenditure was calculated based on poverty lines estimated for 23 areas in Brazil, including metropolitan, urban and rural areas 10 . The values presented in the publication (for September 2004) were deflated for January 2003, the reference date for the survey, and annualized. Deflation was based on the national index of prices for the consumer (INPC) for the period (9.232\%), obtained from IBGE. Household subsistence expenditure was obtained by multiplying per capita values by the adjusted number of residents $(n r)$ through the expression $n r 0.42$. The value 0.42 is the elasticity of food expenditure in relation to household size found from the survey data 1 .

The first stage of analysis included the description of the share of health expenses in relation to total household consumption, as well as shares of medicines, health insurance and other expenses in relation to total health expenditures, overall and according to IEN quintiles. Secondly, we estimated the proportion of households that spent less than $5 \%$, more than $10 \%$ and more than $20 \%$ of their total consumption on health, and also households that spent $40 \%$ or more of their capacity to pay for the country as a whole and in relation to IEN quintiles. The crude and adjusted associations between vulnerability indicators and catastrophic health expenditure $(40 \%+$ of capacity to pay based on household consumption) were estimated with prevalence ratios, their respective 95\% confidence intervals and p-values, obtained by Poisson regression 8 . Vulnerability indicators remained in the regres- sion models according to a backward selection procedure, with only variables associated with $\mathrm{p}$-values $(\mathrm{p}<0.05)$ being kept in the final model. Two-way interactions were explored among the vulnerability indicators. Finally, we plotted on two bar graphs catastrophic health expenditure by IEN quintiles and country region, and the statistically significant interactions found with the Poisson regression.

All analyses were performed taking into account the sampling design, using Stata's svy command set (Stata Corp., College Station, EUA). Crude and adjusted prevalence ratios presented in Table 1 and respective 95\% confidence intervals and p-values were obtained by Poisson regression 11 suitably adjusted for sample design.

\section{Results}

Among the 37,830 urban households surveyed, $28.5 \%$ were headed by a woman, $23.8 \%$ had at least one elderly resident (60 or more years of age), $40.1 \%$ had at least one child, $16.1 \%$ had two or more children, and in $31.4 \%$ of cases, the head of household was covered by health insurance.

On average, $5.1 \%$ of household consumption was spent on health, varying from $4.4 \%$ among the poorest $20 \%$ to $6 \%$, among the $20 \%$ better-off (Table 2). Expressive differences were observed for the share of health items as part of total health spending - among the poorest, $78.3 \%$ were related to medicines, compared to $36.5 \%$ among the better-off. Conversely, the poorest spent only $3.5 \%$ on health insurance, less than a tenth of the $37.5 \%$ spent by the better-off (Table 2).

The proportions of households with health expenditure $\leq 5 \%$, and in excess of $10 \%$ and $20 \%$ of their consumption are presented in Table 3 . Overall, these proportions were $64.9 \%, 15.5 \%$ and $3.8 \%$, respectively. The proportions of households spending $5 \%$ or less in health increased with lower socioeconomic position. Among the poorest $20 \%, 71.6 \%$ of households spent $5 \%$ or less, compared to $54.2 \%$ among the richest $20 \%$. The association of expenditure in excess of $20 \%$ of household consumption was in the same direction $-4.2 \%$ among the poorest compared to $2.9 \%$ among the better-off. Health spending in excess of $10 \%$ of consumption showed an association in the opposite direction - it was more common among the better-off (17.9\%) than among the poorest (13.1\%).

A more sophisticated way to explore excessive spending is to use the household capacity to pay as the denominator, instead of total consumption (Table 3). Again, we found a strong negative association of spending in excess of 
Potential predictors of catastrophic health expenditure *. Effects are presented as prevalence ratios, crude and adjusted by Poisson regression. Brazilian Household Budget Survey, 2002-2003.

\begin{tabular}{|c|c|c|c|c|c|}
\hline & \multicolumn{2}{|c|}{ Crude associations } & \multicolumn{3}{|c|}{ Adjusted associations } \\
\hline & Prevalence ratio & $p$-value & Prevalence ratio & Prevalence ratio & $\mathrm{p}$-value \\
\hline \multirow[t]{2}{*}{ IEN reference quintiles } & & $<0.001$ & \multicolumn{2}{|c|}{ Health insurance ** } & $<0.013 * \star \star$ \\
\hline & & & no & yes & \\
\hline 1 & $7.6(4.0-14.6)$ & & $19.8(6.8-57.8)$ & $15.8(4.8-51.7)$ & \\
\hline 2 & $3.5(1.7-6.9)$ & & $7.1(2.3-21.7)$ & $20.9(6.3-69.0)$ & - \\
\hline 3 & $1.8(0.9-3.8)$ & & $3.7(1.1-12.0)$ & $7.8(2.3-26.3)$ & - \\
\hline 4 & $1.2(0.5-2.7)$ & & $2.3(0.5-11.2)$ & $3.9(1.1-13.6)$ & - \\
\hline 5 & 1.0 & & 1.0 & $3.4(0.9-12.1)$ & - \\
\hline Head of household is female & $1.5(1.2-1.9)$ & 0.001 & \multicolumn{2}{|c|}{-} & - \\
\hline Skin color/race of household head & & 0.106 & \multicolumn{2}{|c|}{-} & - \\
\hline White & 1.0 & & \multicolumn{2}{|c|}{-} & \\
\hline Black & $1.0(0.7-1.6)$ & & \multicolumn{2}{|c|}{-} & \\
\hline Mixed/other & $1.3(1.0-1.7)$ & & \multicolumn{2}{|c|}{-} & \\
\hline Elder in household (1+) & $2.7(2.2-3.4)$ & $<0.001$ & \multicolumn{2}{|c|}{$2.4(1.9-3.0)$} & $<0.001$ \\
\hline Child in household (2+) & $1.3(0.9-1.6)$ & 0.112 & \multicolumn{2}{|c|}{-} & - \\
\hline Health insurance & $0.7(0.5-0.9)$ & 0.004 & \multicolumn{2}{|c|}{$-\#$} & - \\
\hline
\end{tabular}

IEN: National Economic Indicator (in portuguese).

* Catastrophic health expenditure defined as health spending equal to or greater than $40 \%$ of consumption-based capacity to pay;

** Given that an interaction was found, prevalence ratios are shown for each group of socioeconomic position (measured by IEN) and health insurance coverage, relative to the richest group not covered by health insurance;

*** $p$-value refers to the interaction terms between IEN and health insurance;

\# Estimates presented along with quintiles of IEN due to the interaction found.

\section{Table 2}

Share of health expenses in relation to total household consumption and shares of medicines, health insurance and other expenses in relation to total health expenditures. Brazilian Household Budget Survey, 2002-2003.

\begin{tabular}{|c|c|c|c|c|c|c|c|}
\hline \multirow[t]{2}{*}{ Description } & \multirow[t]{2}{*}{ All } & \multicolumn{5}{|c|}{ National Economic Indicator quintiles with reference to Brazil } & \multirow[t]{2}{*}{$p$-value } \\
\hline & & RQ1 & RQ2 & RQ3 & RQ4 & RQ5 & \\
\hline \multicolumn{8}{|c|}{$\%$ in relation to total household consumption } \\
\hline Total health expenses & 5.1 & 4.4 & 4.7 & 5.1 & 5.7 & 6.0 & $<0.001$ \\
\hline \multicolumn{8}{|c|}{$\%$ in relation to total health expenditure } \\
\hline Medicines & 60.2 & 78.3 & 70.4 & 63.3 & 51.7 & 36.5 & $<0.001$ \\
\hline Health insurance & 16.4 & 3.5 & 7.5 & 12.3 & 22.2 & 37.5 & $<0.001$ \\
\hline Other expenses & 23.4 & 18.2 & 22.1 & 24.4 & 26.1 & 26.0 & $<0.001$ \\
\hline
\end{tabular}

RQ: reference quintile.

$40 \%$ of capacity to pay with socioeconomic position. Among the poorest, $4.4 \%$ of households were in this situation, compared to only $0.6 \%$ among the richest $20 \%$. That is, the poorest presented a risk that was more than seven times greater of experiencing catastrophic health spending. We also present the proportions of households with spending in excess of $40 \%$ of capacity to pay based on reported income. The proportions are much higher than those found for capacity to pay based on consumption - highlighting the problems of using income estimates.

The analysis of catastrophic expenditure by country region is shown in Figure 1. The South Region showed the lowest proportions of catastrophic spending among the $20 \%$ poorest (3\%). 
Proportion of households that spent less than $5 \%$, and more than 10 and $20 \%$ of their total consumption with health and that spent $40 \%$ or more of their capacity to pay, according to reference quintiles of the IEN (National Economic Indicator) relative to Brazil (RQ). Brazilian Household Budget Survey, 2002-2003.

\begin{tabular}{|c|c|c|c|c|c|c|c|}
\hline \multirow[t]{3}{*}{ Level of health expenditure } & \multirow[t]{3}{*}{ All } & \multicolumn{6}{|c|}{ Proportion of expenses on health $(95 \% \mathrm{Cl})$} \\
\hline & & \multicolumn{5}{|c|}{ IEN reference quintiles with reference to Brazil } & \multirow[b]{2}{*}{ p-value * } \\
\hline & & RQ1 & RQ2 & RQ3 & RQ4 & RQ5 & \\
\hline \multicolumn{8}{|l|}{ Relative to total consumption } \\
\hline$\leq 5 \%$ & $64.9(63.8-65.8)$ & $71.6(70.1-73.1)$ & $69.1(67.1-71.1)$ & $65.5(63.5-67.4)$ & $60.2(57.8-62.7)$ & $54.2(51.6-56.8)$ & $<0.001$ \\
\hline$\geq 10 \%$ & $15.5(14.8-16.3)$ & $13.1(12.0-14.1)$ & $14.4(12.9-15.8)$ & $15.1(13.5-16.7)$ & $17.7(16.0-19.4)$ & $17.9(15.9-19.9)$ & $<0.001$ \\
\hline$\geq 20 \%$ & $3.8(3.4-4.1)$ & $4.2(3.6-4.8)$ & $4.0(3.2-4.8)$ & $3.6(2.9-4.2)$ & $3.5(2.7-4.2)$ & $2.9(2.3-3.6)$ & 0.006 \\
\hline \multicolumn{8}{|l|}{ Relative to capacity to pay } \\
\hline$\geq 40 \%$ (consumption based) & $2.0(1.7-2.2)$ & $4.4(3.8-5.0)$ & $2.0(1.4-2.5)$ & $1.0(0.7-1.4)$ & $0.7(0.3-1.0)$ & $0.6(0.2-0.9)$ & $<0.001$ \\
\hline$\geq 40 \%$ (income based) & $11.7(11.0-12.3)$ & $22.1(20.8-23.3)$ & $13.7(12.3-15.1)$ & $9.2(8.0-10.5)$ & $5.6(4.6-6.7)$ & $3.5(2.5-4.5)$ & $<0.001$ \\
\hline
\end{tabular}

RQ: reference quintile.

* Test for linear trend.

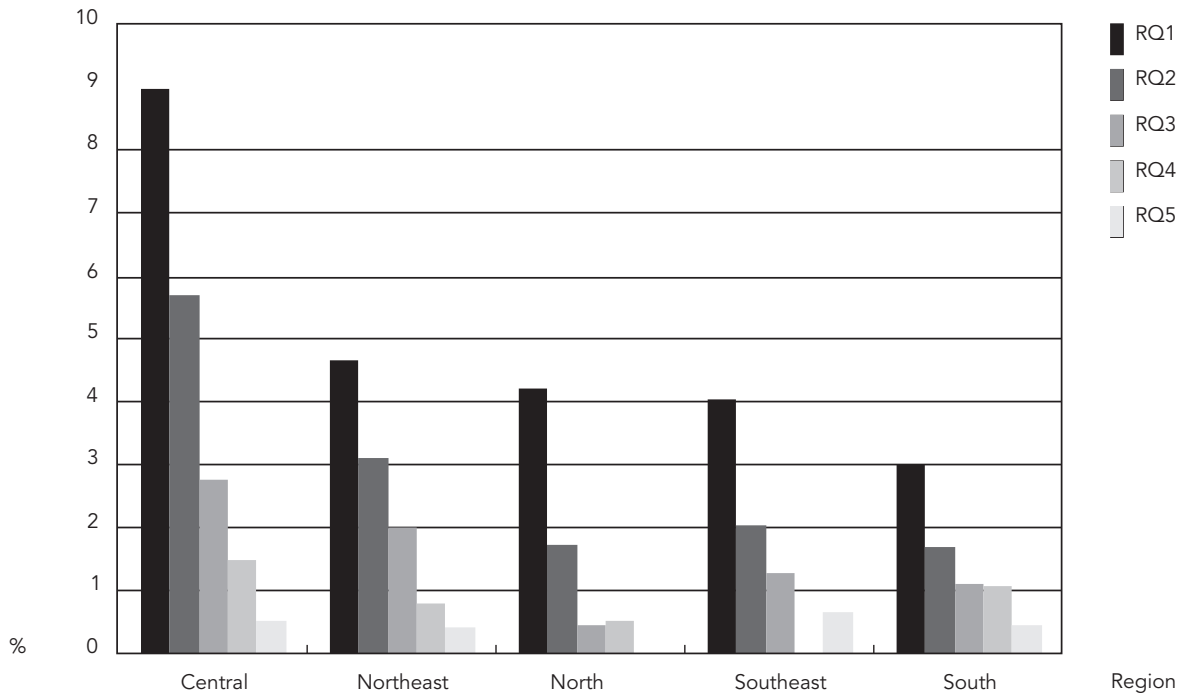

The North, Northeast and Southeast were similar in this respect (around 4\%). The Midwest region showed a much higher proportion of catastrophic spending for the three lowest wealth quintiles. In all regions the same trend of decreasing catastrophic spending with higher socio-economic position was observed.
Finally, we explored vulnerability indicators for catastrophic health spending. Socioeconomic position, sex and color/race of the head of household, presence of an elderly person and two or more children, and coverage by health insurance were studied. Results are presented in Table 1. The crude analysis showed that socioeconomic 
position, sex of the head of household, presence of an elderly person and health insurance were associated with catastrophic health spending. At this point, coverage by health insurance presented a protective effect $(\mathrm{PR}=0.7)$. In the adjusted analysis through Poisson regression, the effect of the sex of household head was reduced to the point of losing its statistical significance. An interaction between socio-economic position and health insurance was found, suggesting that households with health insurance are, in most cases, exposed to a greater risk of catastrophic health spending that those that are uninsured. Prevalence ratios for each grouping of socioeconomic position and health insurance are shown in Table 1, relative to the households in the highest IEN reference quintile which are uninsured. The adjusted proportions of catastrophic spending for each group are shown in Figure 2. The effect of at least one elder in the household kept its independent effect, reduced slightly to a prevalence ratio of 2.4 .

\section{Discussion}

The POF is the most complete national survey to record household expenses for every item possible. This makes this survey especially suitable for estimating health expenditure and its share on total household consumption. In this survey, income is also recorded in detail, so that health spending can also be compared to total household income. This is important, since several definitions have been used for catastrophic health expenditure in the literature 1,12,13. The solid methodology and the experience that the IBGE has gathered in collecting this kind of data adds to the quality of the data. The main limitation of the data is related to the reference period for health expenses - just 30 days. As illness is most commonly an acute event - e.g. an infection, a heart attack, a stroke - relying on just 30 days of health spending, and annualizing it, may lead to over- or underestimation of household health spending. As our estimates of catastrophic spending rely on individualized household data, this may represent a problem.

Our results relating to the share of health spending in relation to total consumption is remarkably similar to what was found recently in urban India 5 (4.4\%). A similar trend was also found in this study, with the share of health spending growing with SEP. Using the same source of data, but analyzing the share of health expenses in relation to income, Uga \& Santos 14

\section{Figure 2}

Catastrophic health expenditure (40\%+ of capacity to pay based on household consumption) by National Economic Indicator reference quintiles and private health insurance (based on adjusted model with interaction shown in Table 3). Brazilian Household Budget Survey, 2002-2003.

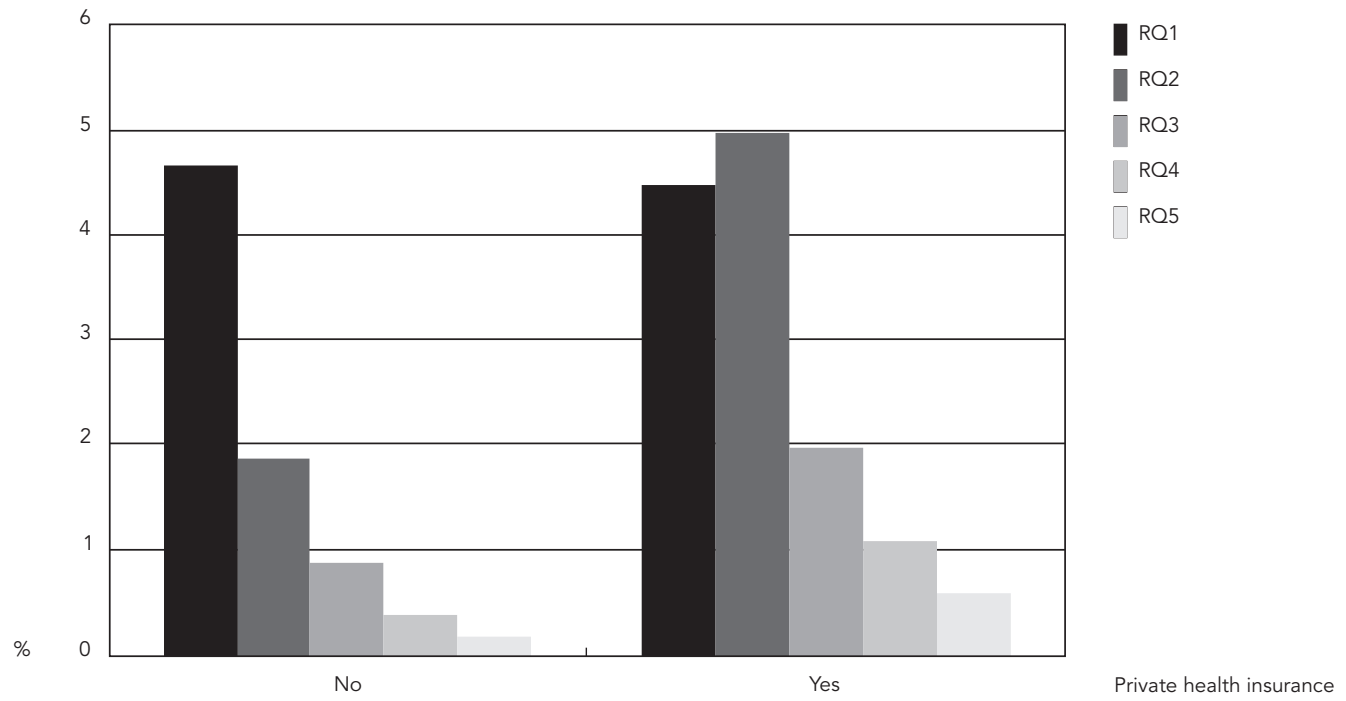


found an association in the opposite direction highlighting the important differences between income and consumption. Diniz et al. 15, who also analyzed the POF 2002/2003 survey, present a similar analysis in their Table 1 where the trend and estimated results are very close to ours.

When measured relative to household income, the share of health spending has been shown to be about twice as high $-10.5 \%$ in a local study in South Brazil 7 and between $8 \%$ and $13 \%$ in a national analysis of Brazil 16. Uga \& Santos 14 showed lower shares, varying from $7 \%$ to $3 \%$ from the $10 \%$ poorest to the $10 \%$ richest.

The proportion of health spending taken by medicines was also similar to what was reported for India $5-70 \%$. For Brazil we found an average of $60 \%$, but the difference between SEP quintiles was much greater here than in India where it varied from $83 \%$ to $60 \%$ from the poorest to the richest. Similar results were already shown in several other publications 7,14,15,16.

The estimates we found for the different definitions of catastrophic health expenditure varied widely, as well as the directions of association with socio-economic position. The estimate based on capacity to pay relative to consumption was the lowest ( $2 \%$ overall) and the one with the strongest association with socio-economic position. The risk of catastrophic health spending was more than 7 -fold among the poorest relative to the richest. The estimate based on capacity to pay relative to income yielded values about six times higher. Spending more than $20 \%$ of total consumption on health presented intermediate figures. Using the same dataset and attempting a methodological approach similar to Xu et al. 1, also used by us, Diniz et al. 15 found different results from ours - about half the overall prevalence of catastrophic expenditure (at $40 \%$ of household consumption). This is probably due to different calculations of capacity to pay, since the estimates of share of health expenses are comparable.

This wide variation represents the weakness of this indicator, only amplified by the difficulties of collecting reliable income information and the short recall period used for health spending, already mentioned. This weakness is further highlighted by the results obtained by Diniz et al. 15, different from ours. We believe that other strategies should be used to assess the occurrence of excessive health spending. These strategies should enable the assessment of families incurring debts and impoverishment. We are currently testing direct questions on health expenses that lead to financial difficulties, such as borrowing or cutting essential expenditure, that might improve the way excessive spending is assessed.
Regional differences found for catastrophic health spending based on capacity to pay relative to consumption were significant and did not follow a pattern linked to regional economic development. The Central Region showed the largest proportions of catastrophic spending, a region richer than the North and the Northeast. Further work would be needed to pinpoint the reasons. As possible explanations, we suggest our finding that private health insurance policies do not protect households from catastrophic health spending. In fact, some private policies may even increase health expenses through their induced demand for specialized and costly medical services, which are not always covered by them. Brasília, the capital, presents a large number of senior public sector staff, who may be in special need of these services. It has also the highest per capita income in the country, which may add to the unexpected finding. This, in conjunction with towns established not long ago, where public health services might not have had enough time to be sufficiently organized may explain the higher proportion of catastrophic health expenditure in this region of the country. On the other end of the scale, the two richest regions in the country (South and Southeast) presented the lowest proportions of catastrophic spending, which is probably linked to better wages and a better established health system.

In terms of risk markers, the presence of an elderly person in the household was associated with an increased risk, similar to what was reported in studies in Turkey ${ }^{3}$ and the USA ${ }^{6}$. The presence of children and characteristics of the household head did not associate with catastrophic health spending. On the other hand, health insurance, which was expected to protect 3,6 , presented a complex association with catastrophic spending. Coverage by health insurance actually increased the risk of catastrophic spending in all socio-economic quintiles, except for the first (exactly where health insurance coverage is lowest). Risk increased up to 3.4 times for those who had health insurance, leaving a difficult question to answer. The first clue may be in the results presented by Veras et al. 17 in relation to coverage by health insurance by age in the states of Rio de Janeiro and São Paulo - coverage increases with age. Consistent with this finding, we have preliminary evidence from an ongoing qualitative study in Pelotas, that the perception of vulnerable health is one of the main triggers for middle-income families to buy health insurance. Given that we do not have any health indicator available in this survey, it is not possible to adjust for health status or health care need. Thus, the effect attributed by the analyses to health insurance may be just 
confounding. But if insurance would cover all health needs, such effect should not be observed. It is necessary, then, that not only health insurance acts as a marker of ill-health risk, but also that it does not prevent excessive spending. This is not unlikely to happen given the limited coverage of health insurance in Brazil towards medicines, home care, physical therapy, prolonged hospital stay, etc. For the poorest, especially, medicines are the main source of health spending and are likely to be either the main reason for excessive spending, or at least, a concurrent one.

\section{Resumo}

O objetivo deste trabalho foi estimar o gasto catastrófico em saúde no Brasil e identificar indicadores de vulnerabilidade. Dados da Pesquisa de Orçamentos Familiares 2002-2003 foram utilizados para derivar consumo domiciliar total, despesa com saúde e renda domiciliar. Posição socioeconômica foi definida por meio de quintis do Indicador Econômico Nacional, usando pontos de corte de referência para o país. A análise se restringiu a domicílios urbanos. Gasto catastrófico em saúde foi definido como o gasto além de $10 \%$ e $20 \%$ do consumo domiciliar total e além de $40 \%$ da capacidade de pagar. Estimativas do gasto catastrófico em saúde variaram de $2 \%$ a 16\%, dependendo da definição. Para a maioria delas, ele foi mais alto entre os pobres. A Região Centro-oeste apresentou as maiores proporções de gasto catastrófico em saúde, enquanto que o Sul e o Sudeste apresentaram as mais baixas. Presença de um idoso, plano privado de saúde e posição socioeconômica se associaram com o desfecho, sendo que a cobertura por plano de saúde não protegeu contra o gasto catastrófico em saúde.

Gastos em Saúde; Serviços de Saúde; Planos de PréPagamentos em Saúde
Given the variability in estimates for catastrophic health spending based on different definitions, it is not possible to conclude whether it is too high or not in Brazil. The results seem to indicate that it afflicts the poorest more often than the richest, and that private health insurance is not enough to prevent excessive health spending. We believe new approaches are needed to study catastrophic spending in a meaningful way for health systems planning.

\section{Contributors}

A. J. D. Barros proposed the study concept and was responsible for writing up the discussion, as well as the main analysis. J. L. Bastos helped with the literature review and drafted the introduction. All authors reviewed and approved the final manuscript. A. H. Dâmaso drafted the methods and results, as well as tables and carried out the descriptive analyses. 


\section{References}

1. Xu K, Evans DB, Kawabata K, Zeramdini R, Klavus J, Murray CJ. Household catastrophic health expenditure: a multicountry analysis. Lancet 2003; 362:111-7.

2. Yi H, Zhang L, Singer K, Rozelle S, Atlas S. Health insurance and catastrophic illness: a report on the New Cooperative Medical System in rural China. Health Econ 2009; 18 Suppl 2:S119-27.

3. Yardim MS, Cilingiroglu N, Yardim N. Catastrophic health expenditure and impoverishment in Turkey. Health Policy 2010; 94:26-33.

4. Gotsadze G, Zoidze A, Rukhadze N. Household catastrophic health expenditure: evidence from Georgia and its policy implications. BMC Health Serv Res 2009; 9:69.

5. Garg CC, Karan AK. Reducing out-of-pocket expenditures to reduce poverty: a disaggregated analysis at rural-urban and state level in India. Health Policy Plan 2009; 24:116-28.

6. Bennett KJ, Dismuke CE. Families at financial risk due to high ratio of out-of-pocket health care expenditures to total income. J Health Care Poor Underserved 2010; 21:691-703.

7. Barros AJ, Bertoldi AD. Out-of-pocket health expenditure in a population covered by the Family Health Program in Brazil. Int J Epidemiol 2008; 37:758-65.

8. Barros AJ, Victora CG. A nationwide wealth score based on the 2000 Brazilian demographic census. Rev Saúde Pública 2005; 39:523-9.

9. Wagstaff A, van Doorslaer E. Catastrophe and impoverishment in paying for health care: with applications to Vietnam 1993-1998. Health Econ 2003; 12:921-34.
10. Rocha S. Pobreza e indigência no Brasil - algumas evidências empíricas com base na PNAD 2004. Nova Econ 2006; 16:265-99.

11. Barros AJ, Hirakata VN. Alternatives for logistic regression in cross-sectional studies: an empirical comparison of models that directly estimate the prevalence ratio. BMC Med Res Methodol 2003; $3: 21$.

12. Wyszewianski L. Financially catastrophic and high-cost cases: definitions, distinctions, and their implications for policy formulation. Inquiry 1986; 23:382-94.

13. Berki SE. A look at catastrophic medical expenses and the poor. Health Aff (Millwood) 1986; 5:13845.

14. Uga MA, Santos IS. An analysis of equity in Brazilian health system financing. Health Aff (Millwood) 2007; 26:1017-28.

15. Diniz BPC, Servo LMS, Piola SF, Eirado M. Gasto das famílias com saúde no Brasil: evolução e debate sobre gasto catastrófico. In: Silveira FG, Servo LMS, Menezes T, Piola SF, editors. Gasto e consumo das famílias brasileiras contemporâneas. Brasília: Instituto de Pesquisa Econômica Aplicada; 2007.

16. Silveira FG, Osório RG, Piola SF. Os gastos das famílias com saúde. Ciênc Saúde Coletiva 2002; 7:719-31.

17. Veras RP, Caldas CP, Araujo DV, Kuschnir R, Mendes W. Demographic characteristics of elderly people provided with supplementary health care. Rev Saúde Pública 2008; 42:497-502.

Submitted on 15/Jun/2010

Final version resubmitted on 17/Nov/2010

Approved on 24/Nov/2010 